\title{
Solar-Energy Drying Systems
}

\author{
Feyza Akarslan \\ Department of Textile Engineering, Engineering and Architectural Faculty, \\ Süleyman Demirel Univercity, Isparta \\ Turkey
}

\section{Introduction}

Energy is important for the existence and development of humankind and is a key issue in international politics, the economy, military preparedness, and diplomacy. To reduce the impact of conventional energy sources on the environment, much attention should be paid to the development of new energy and renewable energy resources. Solar energy, which is environment friendly, is renewable and can serve as a sustainable energy source. Hence, it will certainly become an important part of the future energy structure with the increasingly drying up of the terrestrial fossil fuel. However, the lower energy density and seasonal doing with geographical dependence are the major challenges in identifying suitable applications using solar energy as the heat source. Consequently, exploring high efficiency solar energy concentration technology is necessary and realistic (Xie et al., 2011).

Solar energy is free, environmentally clean, and therefore is recognized as one of the most promising alternative energy recourses options. In near future, the large-scale introduction of solar energy systems, directly converting solar radiation into heat, can be looked forward. However, solar energy is intermittent by its nature; there is no sun at night. Its total available value is seasonal and is dependent on the meteorological conditions of the location. Unreliability is the biggest retarding factor for extensive solar energy utilization. Of course, reliability of solar energy can be increased by storing its portion when it is in excess of the load and using the stored energy whenever needed. (Bal et al., 2010).

Solar drying is a potential decentralized thermal application of solar energy particularly in developing countries (Sharma et al., 2009). However, so far, there has been very little field penetration of solar drying technology. In the initial phase of dissemination, identification of suitable areas for using solar dryers would be extremely helpful towards their market penetration.

Solar drying is often differentiated from "sun drying" by the use of equipment to collect the sun's radiation in order to harness the radiative energy for drying applications. Sun drying is a common farming and agricultural process in many countries, particularly where the outdoor temperature reaches $30^{\circ} \mathrm{C}$ or higher. In many parts of South East Asia, spice $\mathrm{s}$ and herbs are routinely dried. However, weather conditions often preclude the use of sun drying 
because of spoilage due to rehydration during unexpected rainy days. Furthermore, any direct exposure to the sun during high temperature days might cause case hardening, where a hard shell develops on the outside of the agricultural products, trapping moisture inside. Therefore, the employment of solar dryer taps on the freely available sun energy while ensuring good product quality via judicious control of the radiative heat. Solar energy has been used throughout the world to dry products. Such is the diversity of solar dryers that commonly solar-dried products include grains, fruits, meat, vegetables and fish. A typical solar dryer improves upon the traditional open-air sun system in five important ways (Sharma et al., 2009):

- It is faster. Matetrials can be dried in a shorter period of time. Solar dryers enhance drying times in two ways. Firstly, the translucent, or transparent, glazing over the collection area traps heat inside the dryer, raising the temperature of the air. Secondly, the flexibility of enlarging the solar collection area allows for greater collection of the sun's energy.

- It is more efficient. Since materials can be dried more quickly, less will be lost to spoilage immediately after harvest. This is especially true of products that require immediate drying such as freshly harvested grain with high moisture content. In this way, a larger percentage of product will be available for human consumption. Also, less of the harvest will be lost to marauding animals and insects since the products are in safely enclosed compartments.It is hygienic. Since materials are dried in a controlled environment, they are less likely to be contaminated by pests, and can be stored with less likelihood of the growth of toxic fungi.It is healthier. Drying materials at optimum temperatures and in a shorter amount of time enables them to retain more of their nutritional value such as vitamin C. An added bonus is that products will look better, which enhances their marketability and hence provides better financial returns for the farmers.It is cheap. Using freely available solar energy instead of conventional fuels to dry products, or using a cheap supplementary supply of solar heat, so reducing conventional fuel demand can result in significant cost savings.

\section{Classification of drying systems}

All drying systems can be classifed primarily according to their operating temperature ranges into two main groups of high temperature dryers and low temperature dryers. However, dryers are more commonly classifed broadly according to their heating sources into fossil fuel dryers (more commonly known as conventional dryers) and solar-energy dryers. Strictly, all practically-realised designs of high temperature dryers are fossil fuel powered, while the low temperature dryers are either fossil fuel or solar-energy based systems (Ekechukwu and Norton, 1999).

\subsection{High temperature dryers}

High temperature dryers are necessary when very fast drying is desired. They are usually employed when the products require a short exposure to the drying air. Their operating temperatures are such that, if the drying air remains in contact with the product until equilibrium moisture content is reached, serious over drying will occur. Thus, the products are only dried to the required moisture contents and later cooled. High temperature dryers 
are usually classifed into batch dryers and continuous-flow dryers. In batch dryers, the products are dried in a bin and subsequently moved to storage. Thus, they are usually known as batch-in-bin dryers. Continuous-flow dryers are heated columns through which the product flows under gravity and is exposed to heated air while descending. Because of the temperature ranges prevalent in high temperature dryers, most known designs are electricity or fossil-fuel powered. Only a very few practically-realised designs of high temperature drying systems are solar-energy heated (Ekechukwu and Norton, 1999).

\subsection{Low temperature dryers}

In low temperature drying systems, the moisture content of the product is usually brought in equilibrium with the drying air by constant ventilation. Thus, they do tolerate intermittent or variable heat input. Low temperature drying enables products to be dried in bulk and is most suited also for long term storage systems. Thus, they are usually known as bulk or storage dryers. Their ability to accommodate intermittent heat input makes low temperature drying most appropriate for solar-energy applications. Thus, some conventional dryers and most practically-realised designs of solar-energy dryers are of the low temperature type(Ekechukwu and Norton, 1999).

\section{Types of solar driers}

Solar-energy drying systems are classified primarily according to their heating modes and the manner in which the solar heat is utilised.

In broad terms, they can be classified into two major groups, namely (Ekechukwu and Norton, 1999):

- $\quad$ active solar-energy drying systems (most types of which are often termed hybrid solar dryers); and

- $\quad$ passive solar-energy drying systems (conventionally termed natural-circulation solar drying systems).

Three distinct sub-classes of either the active or passive solar drying systems can be identified which vary mainly in the design arrangement of system components and the mode of utilisation of the solar heat, namely (Ekechukwu and Norton, 1999):

- $\quad$ Direct (integral) type solar dryers;

- İndirect (distributed) type solar dryers.

Direct solar dryers have the material to be dried placed in an enclosure, with a transparent cover on it. Heat is generated by absorption of solar radiation on the product itself as well as on the internal surfaces of the drying chamber. In indirect solar dryers, solar radiation is not directly incident on the material to be dried. Air is heated in a solar collector and then ducted to the drying chamber to dry the product. Specialized dryers are normally designed with a specific product in mind and may include hybrid systems where other forms of energy are also used (Sharma et al., 2009). Although indirect dryers are less compact when compared to direct solar dryers, they are generally more efficient. Hybrid solar systems allow for faster rate of drying by using other sources of heat energy to supplement solar heat. 
The three modes of drying are: (i) open sun, (ii) direct and (iii) indirect in the presence of solar energy. The working principle of these modes mainly depends upon the method of solar-energy collection and its conversion to useful thermal energy.

\subsection{Open sun drying (OSD)}

Fig. 1 shows the working principle of open sun drying by using solar energy. The short wavelength solar energy falls on the uneven product surface. A part of this energy is reflected back and the remaining part is absorbed by the surface. The absorbed radiation is converted into thermal energy and the temperature of product stars increasing. This result in long wavelength radiation loss from the surface of product to ambient air through moist air. In addition to long wavelength radiation loss there is convective heat loss too due to the blowing wind through moist air over the material surface. Evaporation of moisture takes place in the form of evaporative losses and so the material is dried. Further a part of absorbed thermal energy is conducted into the interior of the product. This causes a rise in temperature and formation of water vapor inside the material and then diffuses towards the surface of the and finally losses thermal energy in the and then diffuses towards the surface of the and finally losses the thermal energy in the form of evaporation. In the initial stages, the moisture removal is rapid since the excess moisture on the surface of the product presents a wet surface to the drying air. Subsequently, drying depends upon the rate at which the moisture within the product moves to the surface by a diffusion process depending upon the type of the product (Sodha, 1985).

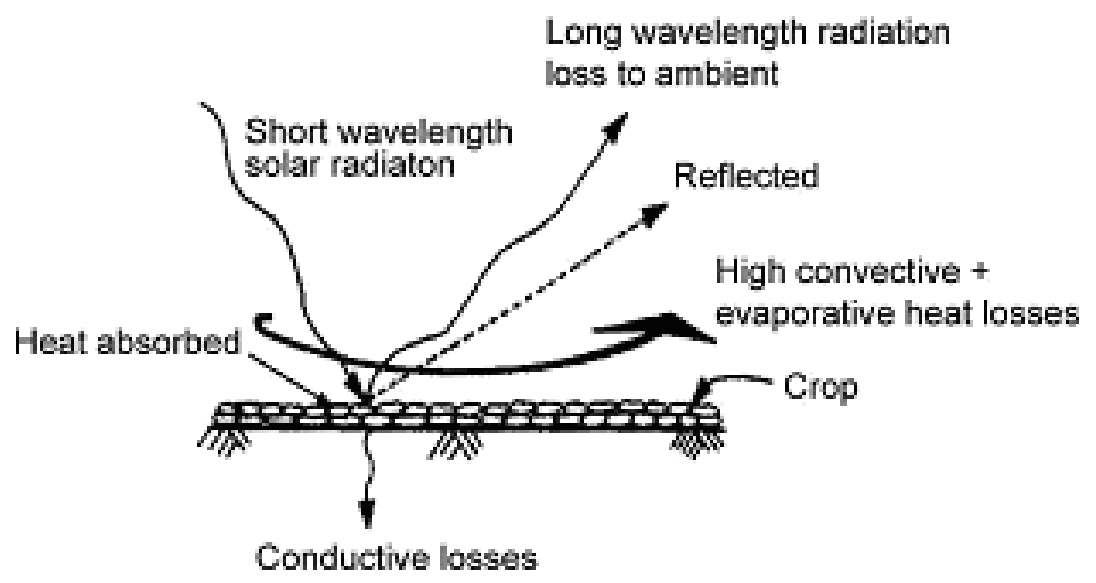

Fig. 1. Working principle of open sun drying.

In open sun drying, there is a considerable loss due to various reasons such as rodents, birds, insects and micro-organisms. The unexpected rain or storm further worsens the situation. Further, over drying, insufficient drying, contamination by foreign material like dust dirt, insects, and micro-organism as well discolouring by UV radiation are characteristic for open sun drying. In general, open sun drying does not fulfill the international quality standards and therefore it cannot be sold in the international market (Sharma et al., 2009). 
With the awareness of inadequacies involved in open sun drying, a more scientific method of solar-energy utilization for drying has emerged termed as controlled drying or solar drying.

The main features of typical designs of the direct an of indirect types solar -energy dryers are illustrated in Table 1.

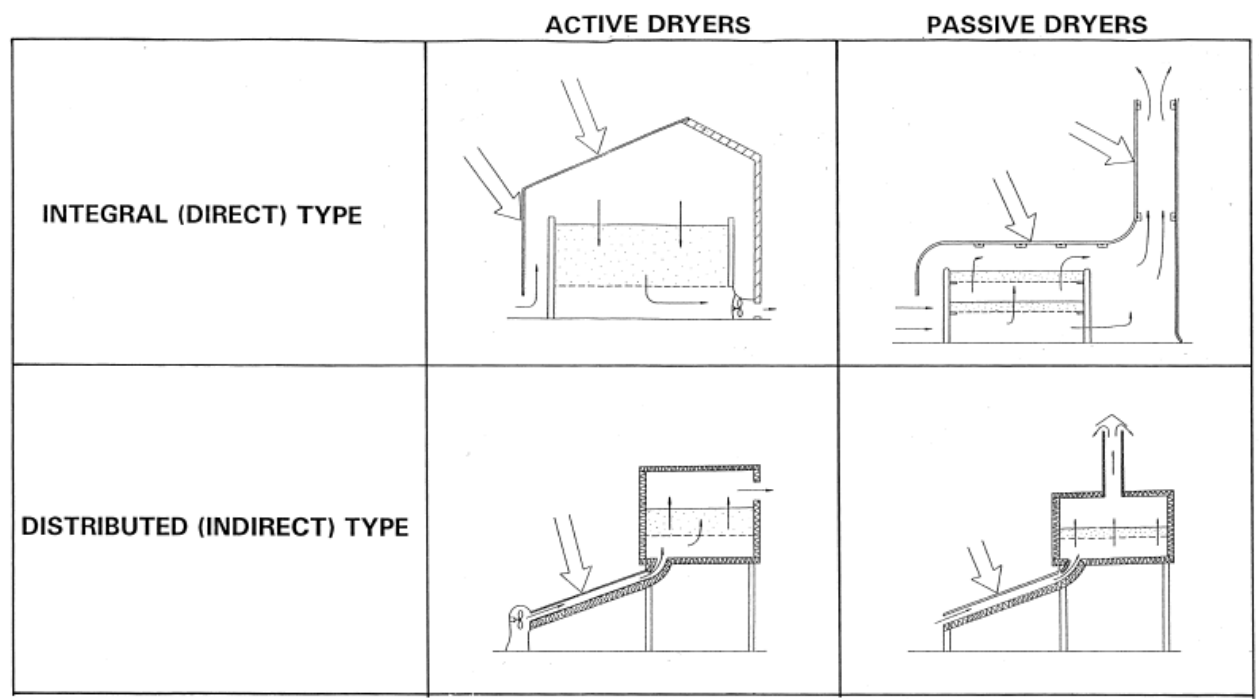

Table 1. Typical solar energy dryer designs (Ekechukwu and Norton, 1999).

\subsection{Direct type solar drying (DSD)}

Direct solar drying is also called natural convection cabinet dryer. Direct solar dryers use only the natural movement of heated air. A part of incidence solar radiation on the glass cover is reflected back to atmosphere and remaining is transmitted inside cabin dryer. Further, a part of transmitted radiation is reflected back from the surface of the product. The remaining part is absorbed by the surface of the material. Due to the absorption of solar radiation, product temperature increase and the material starts emitting long wavelength radiation which is not allowed to escape to atmosphere due to presence of glass cover unlike open sun drying. Thus the temperature above the product inside chamber becomes higher. The glass cover server one more purpose of reducing direct convective losses to the ambient which further become beneficial for rise in product and chamber temperature respectively (Sharma et al., 2009). However, convective and evaporative losses ocur insidethe chamber from the heated material. The moisture is takenaway by the air entering into the chamber from below and escaping through another opening provide at the top as shown in Fig. 2. A direct solar dryer is one in which the material is directly exposed to the sun's rays. This dryer comprises of a drying chamber that is covered by a transparent cover made of glass or plastic. The drying chamber is usually a shallow, insulated box with air-holes in it to allow air to enter and exit the box. The product samples are placed on a perforated tray that allows the air to flow through it and the material. Fig. 2 shows a schematic of a simple direct dryer (Murthy, 2009). Solar radiation passes through the transparent cover and is converted to low-grade heat when it strikes an 
opaque wall. This low-grade heat is then trapped inside the box by what is known as the "greenhouse effect." Simply stated, the short wavelength solar radiation can penetrate the transparent cover. Once converted to low-grade heat, the energy radiates.

Ekechukwu and Norton (1999) reported a modifcation of the typical design. This cabinet dryer (Fig. 3) was equipped with a wooden plenum to guide the air inlet and a long plywood chimney to enhance natural-circulation. This dryer was reported to have accelerated the drying rate about ${ }^{\circledR} v e$ times over open sun drying.

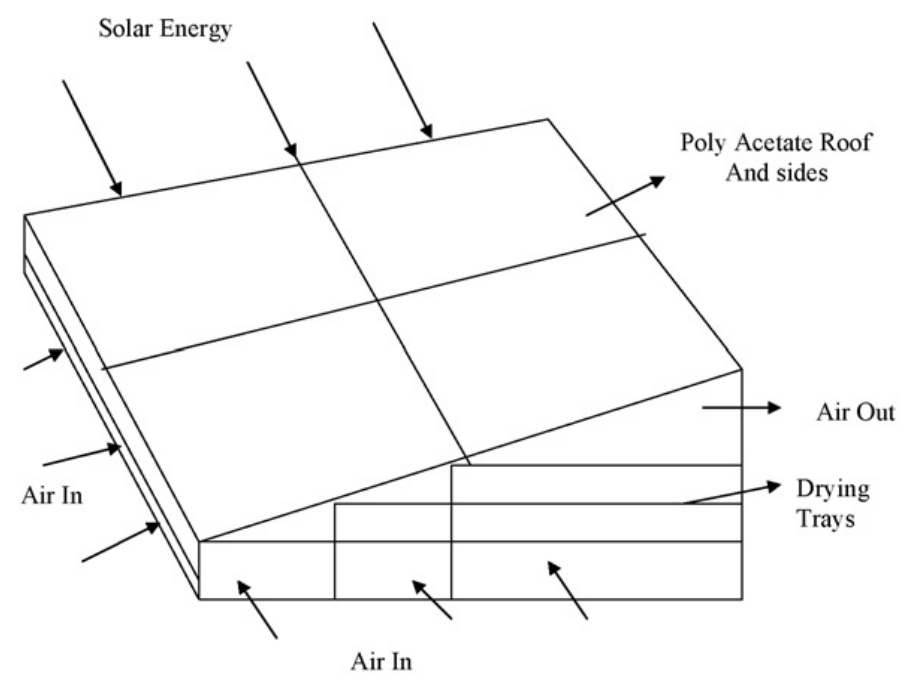

Fig. 2. Direct solar drying (Natural convection type cabinet drier).

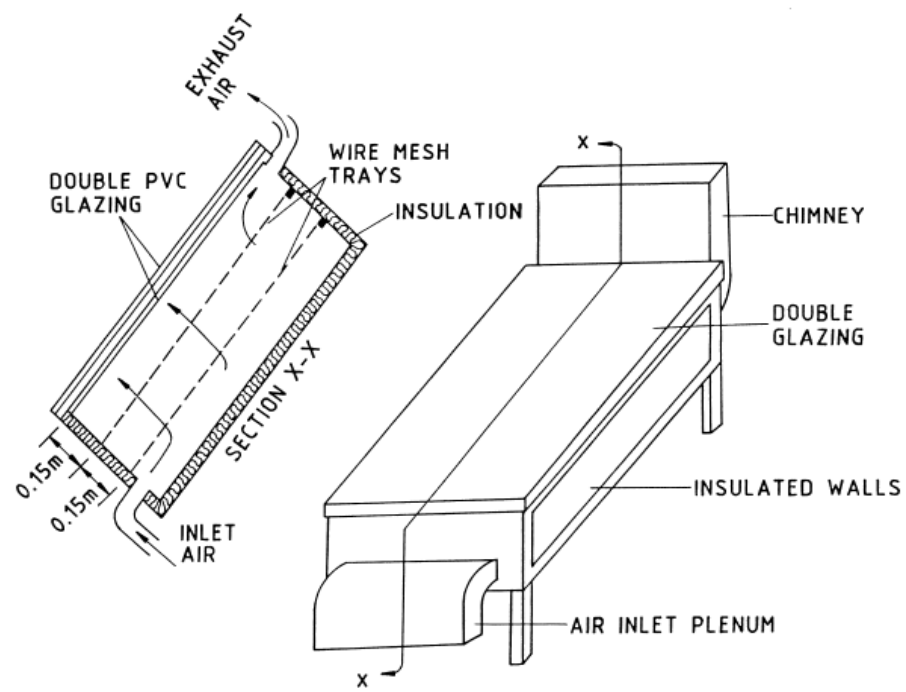

Fig. 3. A modifed natural-circulation solar-energy cabinet dryer. 


\subsection{Indirect type solar drying (ISD)}

The is not directly exposed to solar radiation to minimize discolouration and cracking on the surface of the . Goyal and Tiwari (1999) have proposed and analyzed reverse absorber cabinet dryer (RACD). The schematic view of RACD is shown in Fig. 4 . The drying chamber is used for keeping the in wire mesh tray. A downward facing absorber is fixed below the drying chamber at a sufficient distance from the bottom of the drying chamber. A cylindrical reflector is placed under the absorber fitted with the glass cover on its aperture to minimize convective heat losses from the absorber. The absorber can be selectively coated. The inclination of the glass cover is taken as $45^{\circ}$ from horizontal to receive maximum radiation. The area of absorber and glass cover are taken equal to the area of bottom of drying chamber. Solar radiation after passing through the glass cover is reflected by cylindrical reflector toward a absorber. After absorber, a part of this is lost to ambient through a glass cover and remaining is transferred to the flowing air above it by convection. The flowing air is thus heated and passes through the placed in the drying chamber. The is heated and moisture is removed through a vent provided at the top of drying chamber (Sharma et al., 2009).

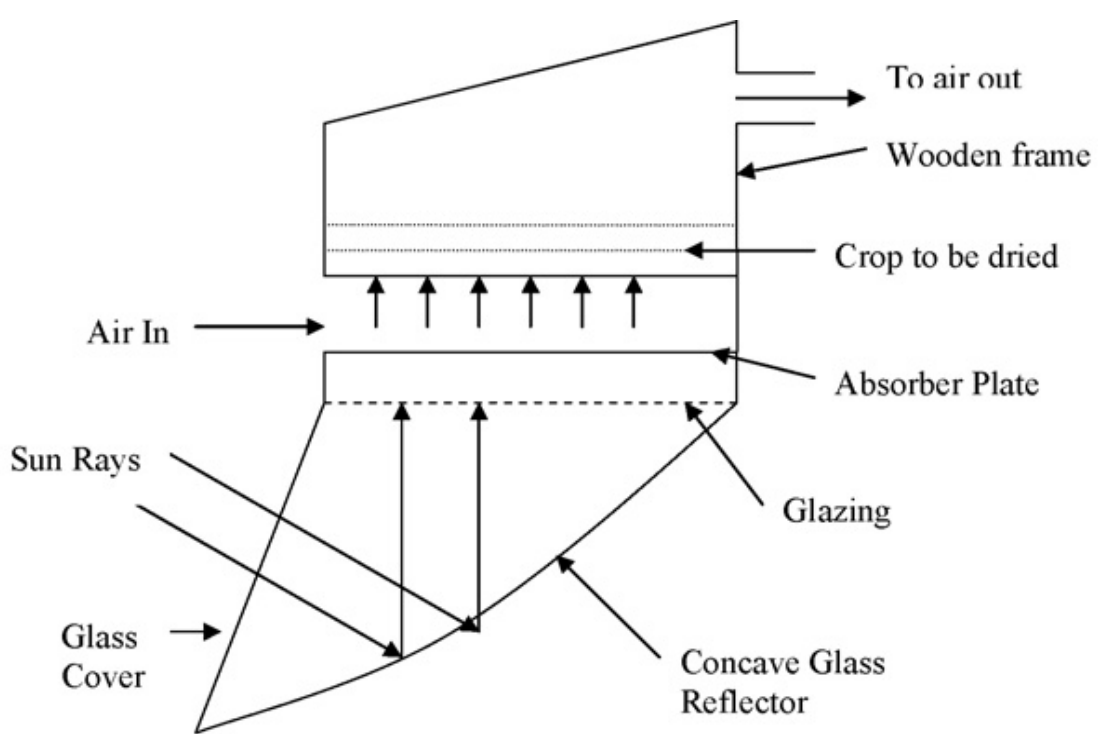

Fig. 4. Reverse absorber cabinet drier.

Fig. 5 describes another principle of indirect solar drying which is generally known as conventional dryer. In this case, a separate unit termed as solar air heater is used for solarenergy collection for heating of entering air into this unit. The air heater is connected to a separate drying chamber where the product is kept. The heated air is allowed to flow through wet material. Here, the heat from moisture evaporation is provided by convective heat transfer between the hot air and the wet material. The drying is basically by the difference in moisture concentration between the drying air and the air in the vicinity of product surface. A better control over drying is achieved in indirect type of solar drying systems and the product obtained is good quality. 


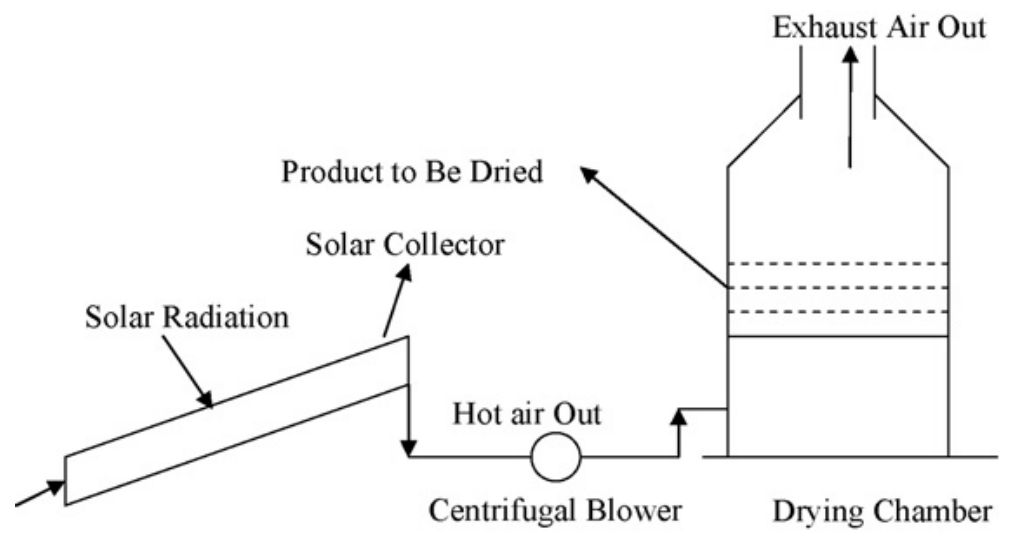

Ambient Air In

Fig. 5. İndirect solar drier ( Forced convection solar drier)

There are several types of driers developed to serve the various purposes of drying products as per local need and available technology. The best potential and popular ones are natural convection cabinet type, forced convection indirect type and green house type. Apart from the above three, as seen from the literature, "Solar tunnel drier" is also found to be popular. These conventional types are shown in Figs 6-7.

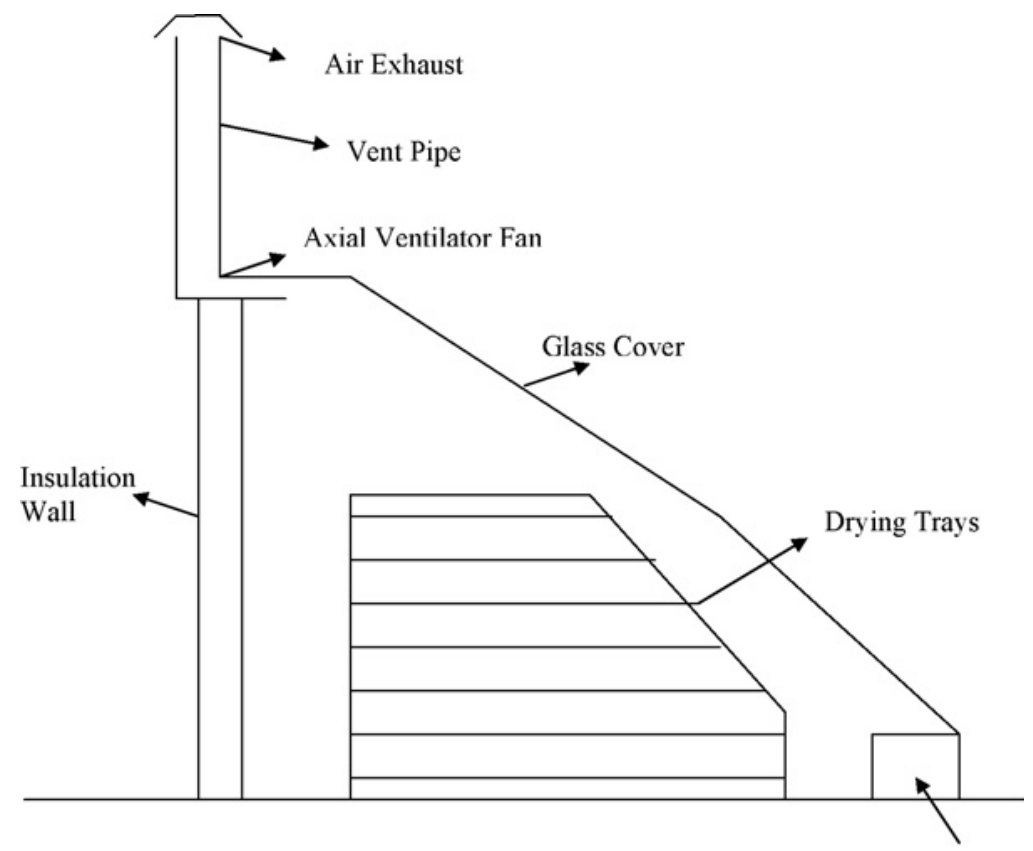

Fresh Air In

Fig. 6. Green house type solar drier. 


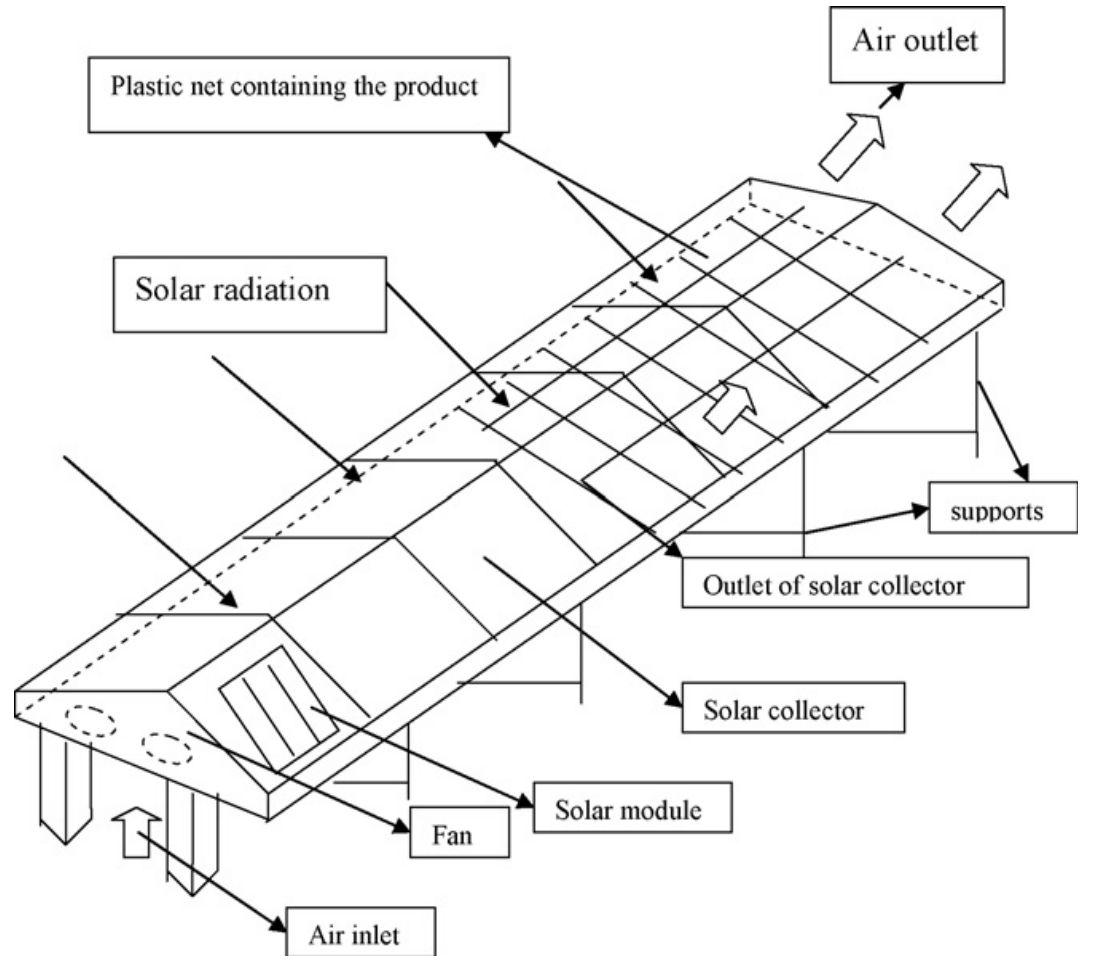

Fig. 7. Solar tunnel drier.

Apart from the obvious advantages of passive solar-energy dryers over the active types (for applications in rural farm locations in developing countries), the advantages of the naturalcirculation solar-energy "ventilated green house dryer" over other passive solar-energy dryer designs include its low cost and its simplicity in both on-the-site construction and operation. Its major drawback is its susceptibility to damage under very high wind speeds. Table 2 gives aconcise comparison of the integral and distributed natural-circulation solarenergy dryers (Ekechukwu and Norton, 1999).

A multi-shelf portable solar dryer (Singh et al., 2004) is developed. It has four main parts, i.e., multi-tray rack, trays, movable glazing and shading plate (see Fig. 8). The ambient air enters from the bottom and moves up through the material loaded in different trays. After passing through the trays, the air leaves from the top. The multirack is inclined depending upon the latitude of the location. Four layers of black HDP sheet are wrapped around the multi-rack such that heat losses are reduced to ambient air from back and sides.

There are seven perforated trays, which are arranged at seven different levels one above the other. The product to be dried is loaded in these trays. To facilitate loading and unloading, a new concept of movable glazing has been developed. It consists of a movable frame (on castor wheels) and UV stabilized plastic sheet. After loading the product, the movable glazing is fixed with the ulti-tray rack so as to avoid any air leakage. 


\begin{tabular}{|c|c|c|}
\hline & \multicolumn{2}{|l|}{ Type } \\
\hline & Integral & Distributed \\
\hline $\begin{array}{l}\text { Principal modes } \\
\text { of heat transfer to } \\
\text { crop }\end{array}$ & $\begin{array}{l}\text { Radiation (ie. By direct absorption of solar } \\
\text { radiation) and convection (ie. from heated } \\
\text { surrounding air). }\end{array}$ & $\begin{array}{l}\text { Convection from pre-heated air in an air- } \\
\text { heating solar-energy collector. }\end{array}$ \\
\hline Components & Glazed drying chamber and chimney. & $\begin{array}{l}\text { Air-heating solar-energy collector, ducting, } \\
\text { drying chamber and chimney. }\end{array}$ \\
\hline Initial cost & Increasing cost $\ldots \ldots \ldots$ & $\longrightarrow$ \\
\hline $\begin{array}{l}\text { Construction, } \\
\text { operation and } \\
\text { maintenance }\end{array}$ & $\begin{array}{l}\text { Simplicity in both construction (ie. On-the- } \\
\text { site construction) and operation. Requires } \\
\text { little maintenance. }\end{array}$ & $\begin{array}{l}\text { Consists of comparatively elaborate } \\
\text { structures, thus requires more capital } \\
\text { investment in materials and large running } \\
\text { costs. More operational difficulties of loading } \\
\text { and occasional stirring of the crop (since } \\
\text { crops are usually dried in relatively deep } \\
\text { layers). }\end{array}$ \\
\hline Efficiency & $\begin{array}{l}\text { Little information on comparison of } \\
\text { performance with distributed-type dryers. } \\
\text { Likely to operate at lower efficiencies due to } \\
\text { its simplicity and less controllability of drying } \\
\text { operations. }\end{array}$ & $\begin{array}{l}\text { Have a tendency to higher efficiency since } \\
\text { individual components can be designed to } \\
\text { optimal performance. }\end{array}$ \\
\hline
\end{tabular}

Table 2. Comparisons of natural-circulation solar-energy dryers

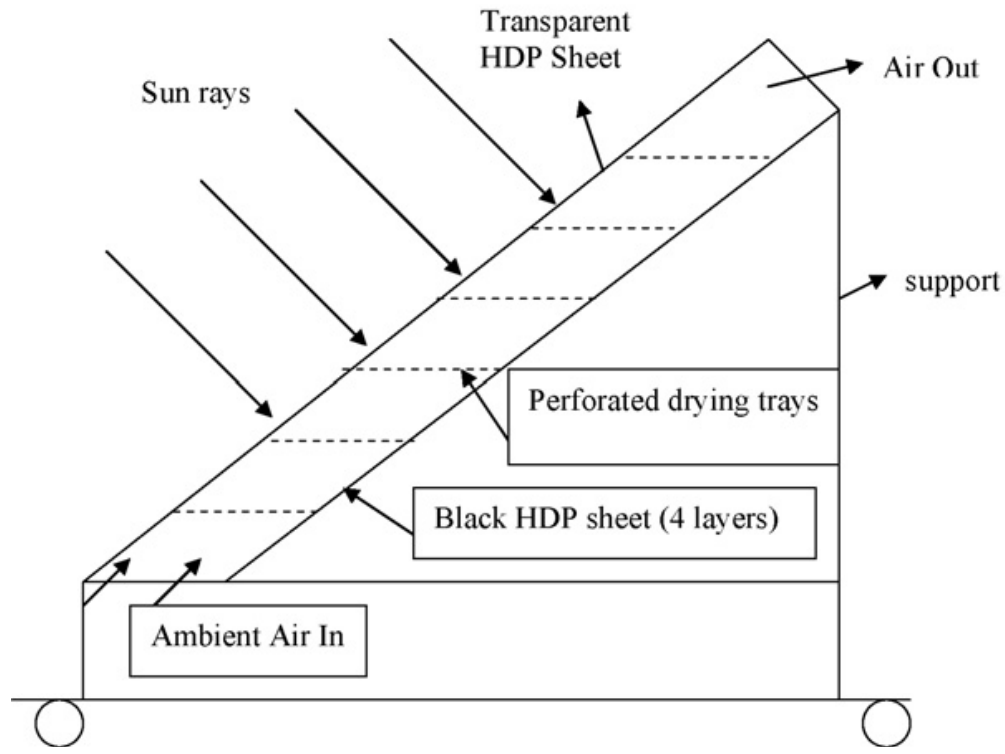

Fig. 8. Multiple-shelf portable solar drier.

A staircase type dryer (Hallak et al., 1996) is developed which is in the shape of a metal staircase with its base and sides covered with doublewalled galvanized metal sheets with a cavity filled with nondegradable thermal insulation (see Fig.9). The upper surface is covered with transparent polycarbon sheet to allow the sun's rays to pass through and be trapped. The upper polycarbon glazed surface is divided into three equal parts which can swing open, to provide access to the three compartment inside the dryer. The base of the dryer has four entry 
points. The partition walls between the compartments also have four port holes for easy air flow. Air moves by natural convection as it enters through the bottom and leaves from the top.

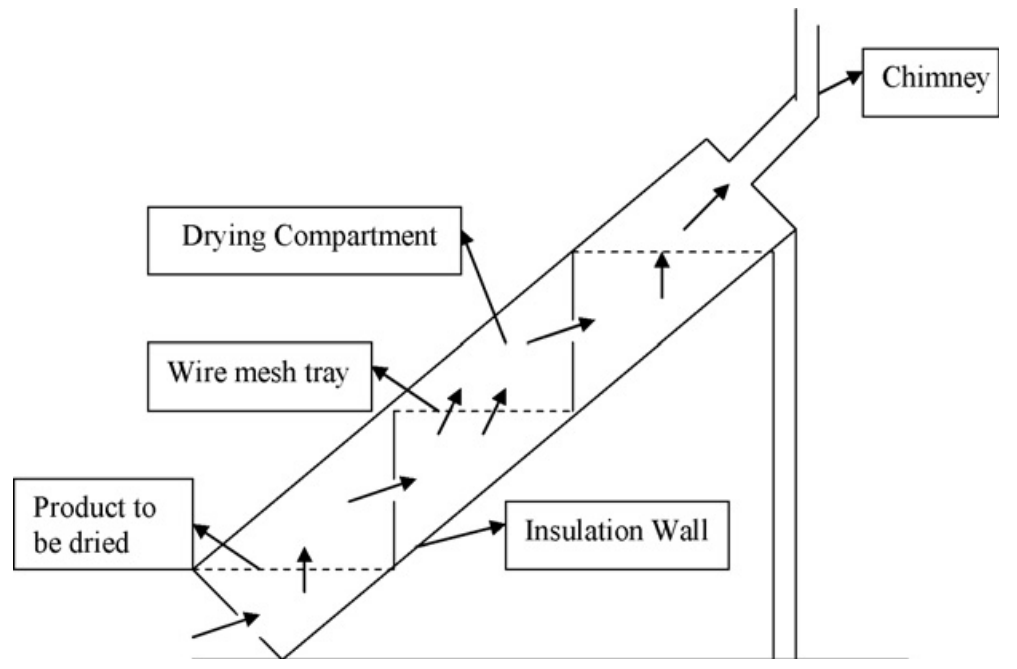

Fig. 9. Staircase solar drier.

Another system called rotary column cylindrical dryer (Sarsilmaz et al., 2000) is developed which contains essentially three parts-air blow region (fan), air heater region (solar collector) and drying region (rotary chamber) (see Fig. 10). A fan with variable speed of air flow rate is connected to the solar collector using a tent fabric. The connection to the dryer or rotary chamber was again through another tent fabric. The dryer is manufactured from wooden plates at the top and bottom and thin ply wood plates at the sides to make cylindrical shape. A rectangular slot is opened on side wall where it faces the solar air heater for the passage of hot air via tent fabric. On the opposite side of this wall a door is provided for loading and unloading of the products. A column is constructed at the center of the rotary chamber to mount the products and the column rotates due to a $12 \mathrm{~V}$ dc motor and a pulley and belt system.

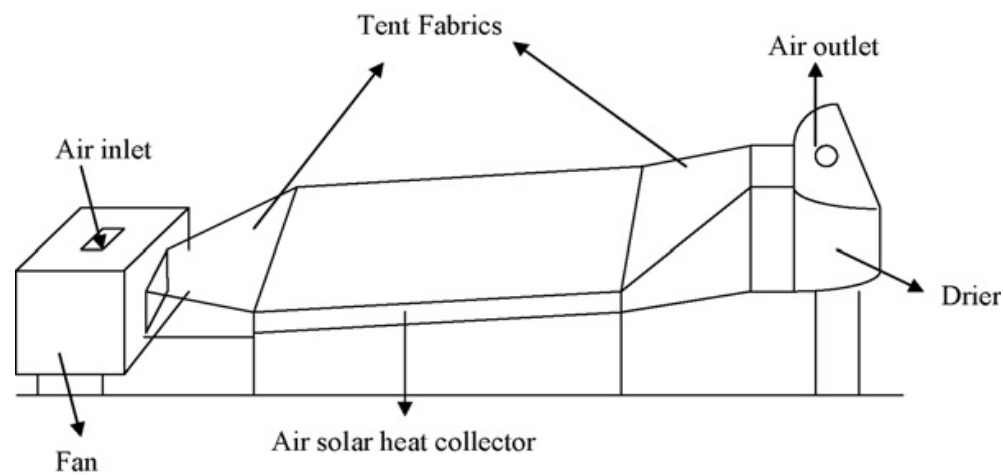

Fig. 10. Rotary column cylindrical drier. 
Other solar assisted drying systems are also developed. The use of V-grooved absorbers improves the heat transfer coefficient between the absorber plate and the air. The present dryer uses collector of the V-groove absorber type (see Fig. 11(a)). A double pass collector is also developed which consists of a porous medium (Othman et al., 2006) in the second pass to store the energy and supply during cloudy weather or in the evenings (see Fig. 11(b)). Some have been improved further by using other methods such as increased convection, etc., which are briefly discussed below.

(a)

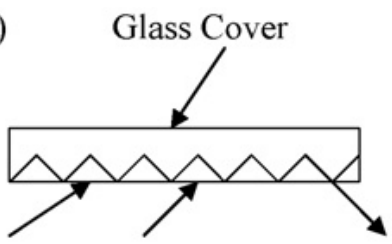

Air inlet V-groove absorber

(b)

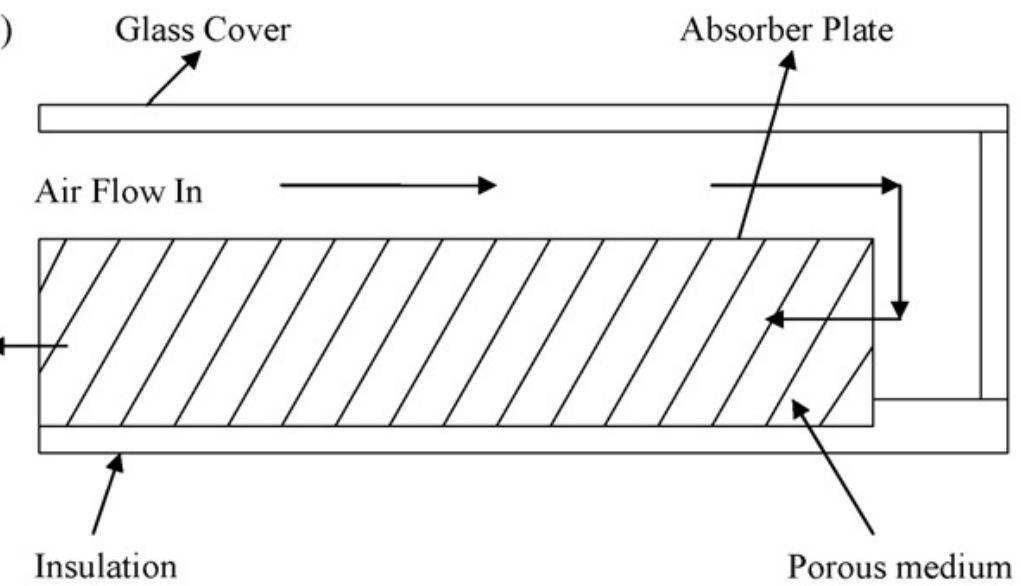

Fig. 11. Solar assisted drying systems.

Since the products need to be spread in a single layer for efficient drying, total tray area available in the dryer for spreading the product is important. In an attempt to acquire the area, the roof top of a farm house has been used as a collector. In extension to this type of drier (Janjai and Tung, 2005), a dual purpose of illuminating the room by providing a low temperature roof integrated solar flat plate air heater is introduced. The heated air is used to dry the product grains spread on perforated plates of aluminum and acrylic, inside the room. The perforation size for groundnut and paddy is calculated. In yet another method, a sun tracking system is used along with a dc driven solar fan (Mumba, 1995) for a controlled heating of the product, as shown in Fig. 12. For example, maize requires to be heated below $60{ }^{\circ} \mathrm{C}$ to avoid overheating and microbial attack. A biomass backup heater is used to supplement the heat required for faster drying process (Bena and Fuller, 2002) 
Six different types of cabinet driers (all natural circulation type) are constructed with same fabrication materials and absorber areas, but different height of air gaps, air pass methods and configurations of absorber plates (Koyuncu, 2006). The air flow rate is maintained constant in all the cases. Out of all, the single covered/glazed and the front pass type with black painted aluminum sheet as absorber plate is found to be most efficient. Also, it is found that, the effect of the shape of the absorbing surface on the performance is considerably less.

In order to make the driers cost effective and comparable to open sun drying, natural convection type green house driers (Koyuncu, 2006) are developed and tested. There are two types of driers (see Figs. 13 and 14). The driers are tested without load-without chimney, with load-without chimney and with load-with chimney. When the driers are loaded (pepper in the present case), the efficiency reduces. It is found that the green house driers are increase the air temperature by $5-9 \circ \mathrm{C}$ and the chimney provides better natural circulation of air.

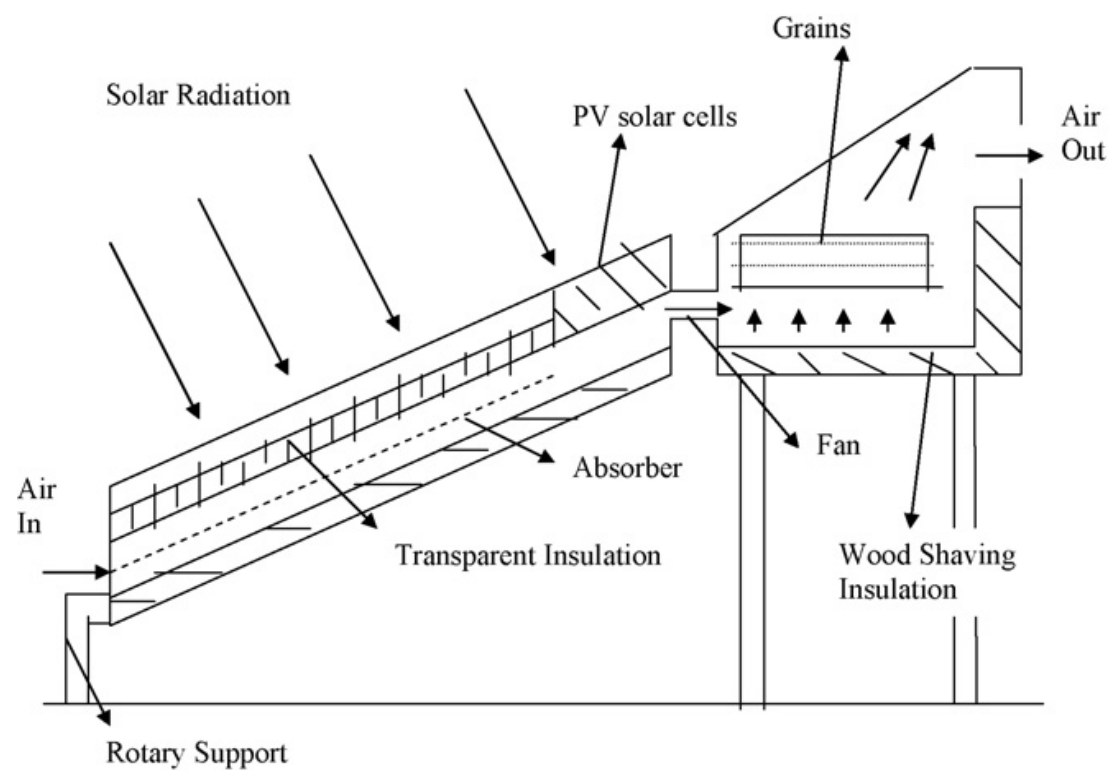

Fig. 12. Solar grain dryer with rotatable indirect air heater and a PV run fan. 

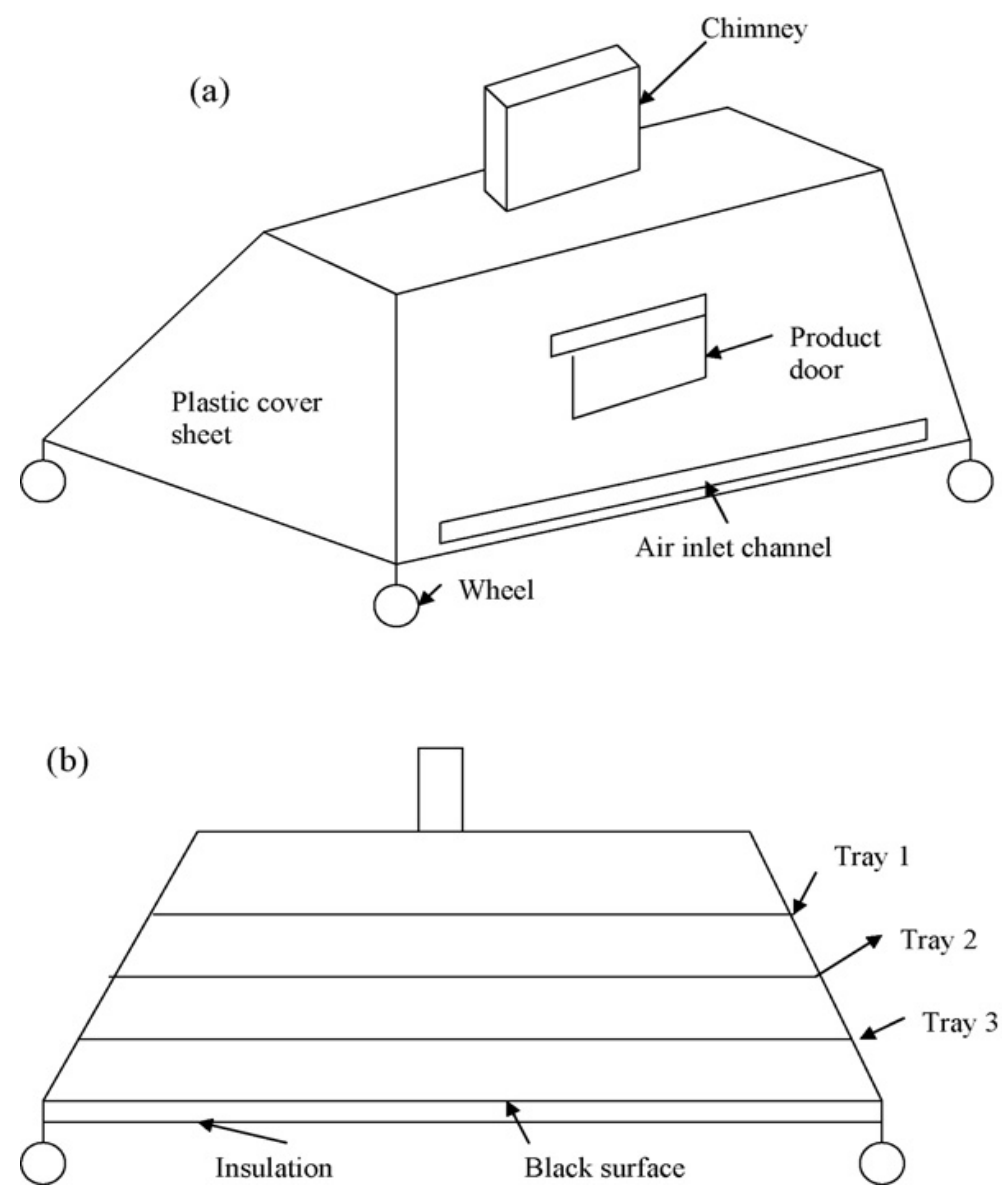

Fig. 13. (a) A simple presentation of first model and (b) side view of first model. 


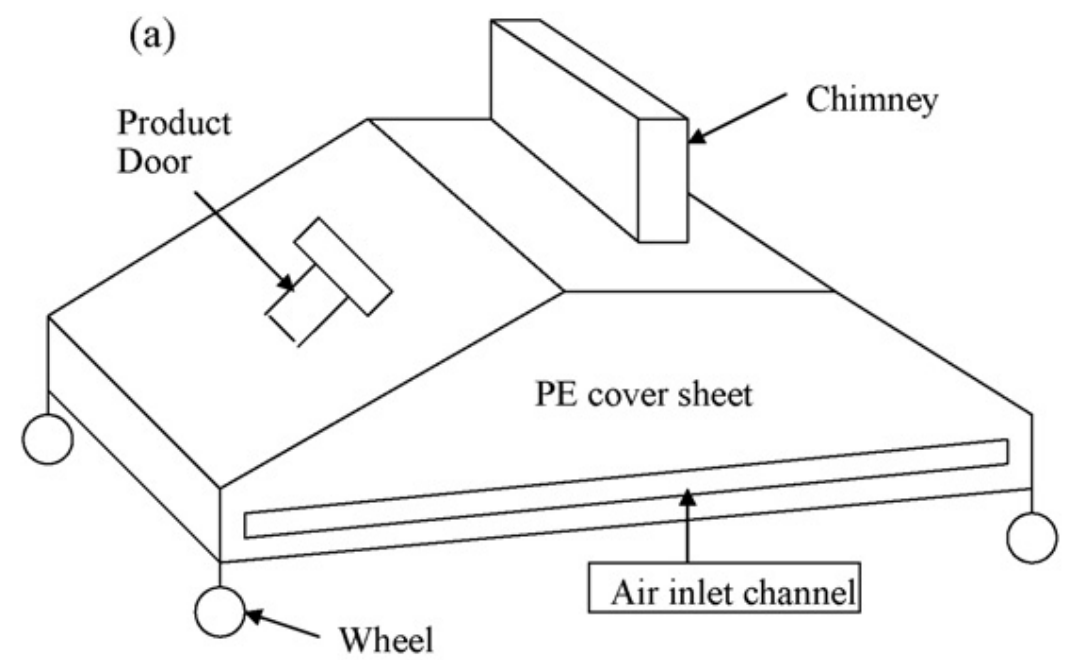

(b)

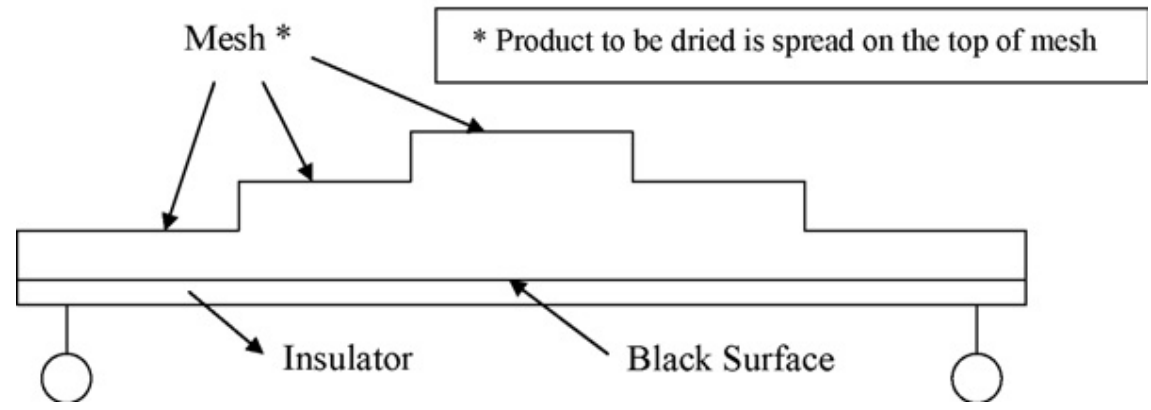

Fig. 14. (a) A simple representation of second model and (b) side view of internal representation of second model.

Totally different methods of drying have been developed which continue to dry the products even in the night times thereby reducing the drying time drastically. The desiccant materials (Shanmugam and Natarajan, 2006) are used which absorb the moisture from the products to be dried. The cost of desiccant materials is high causing the final product cost to be high. Hence, low cost desiccants (Thoruwa et al., 2000) particularly suitable for tropical countries are identified as bentonite-calcium chloride and kaolonite-calcium chloride. Yet another type is the one with thermal storage (sensible) to take care of intermittent incoming solar radiation. The length and width of the air heater, the gap between the absorber plate and glass cover and thickness of the storage material are optimized in this type of drier (Murthy, 2009). The thermal efficiency of the air heater is found to be sufficient for drying of various materials. 
In all the types of driers stated above, the hot air enters the drying chamber and leaves to the atmosphere. But the hot air can be recirculated to save the energy (McDoom et al., 1999). The drying of coconut and cocoa in a scaled down drier of a large scale drier is considered in which the recirculation of hot air yields 31 and $29 \%$ of energy saving, respectively. The recirculation of exhaust/hot air is also applied to hay driers. Lack of uniform drying and inability to accurately predict drying times are some of the existing problems. A new drier is developed which uses forced heated-air circulation through hay stacks. A drying rate difference of $7 \%$ is observed due to recirculation of hot air. By recirculating all of the exhaust air, the previous driers either increased drying time or proved to be uneconomical. So only $30 \%$ of the hot air is recirculated in the present case. The favorable conditions to recirculate the exhaust air are presented (Murthy, 2009).

A drier called FASD (Foldable Agro Solar Dryer) is developed which is a foldable type that can be stored and transported as desired. The performance of the drier is tested to find that the inner temperature is about $8{ }^{\circ} \mathrm{C}$ higher than ambient and humidity is lesser by $6 \%$ inside. Out of all types, the well known heat pump (Murthy, 2009) principle has been used to dry the products and this has been found to be excellent alternative to the solar drying.

\section{Applications of solar driers}

The drying process has been experimentally studied and analyzed to simulate and design a drier. As drying is a process of removing moisture to a safe level, the equilibrium moisture content is defined as the moisture content in equilibrium with the relative humidity of the environment. The equilibrium moisture content is divided into, static and dynamic. While the static is used for food storage process, dynamic is used for drying process. The drying process is experimentally obtained and presented as moisture content on $\mathrm{x}$-axis and rate of drying on y-axis. A deep bed of food grains is assumed to be composed of thin layers normal to the hot air flow direction. The equations for thin layer were written initially, using empirical, theoretical and semitheoretical equations. The conditions of the grain and air, change with position and time during drying of a deep bed of grains. Logarithmic and partial differential equation models to simulate the deep bed dry modeling are dealt in detail (Murthy, 2009).

A computer program in $\mathrm{C}++$ language is developed for modeling of deep bed drying systems and considers eight different configurations of flow of hot air over absorber plates of solar collectors. The usual parameters such as heat removal factor, overall loss coefficient, top loss coefficient, etc., can be determined. The model prompts for basic data (Murthy, 2009) such as amount of grain to be dried, initial moisture content, number of thin layers and weather data.

In a different direction, the first and second law of thermodynamics (Torres-Reyes et al., 2002) have been used to develop the design methods for a particular application. Semi-empirical formulae are developed to calculate the rise in air temperature as it passes through the heater. NTU (number of transfer units) has been defined analogous to the heat exchangers, as a part of design. Using entropy balance the maximum temperature reached by solar collector is written and then Entropy Generation Number is developed to find the entropy generated during thermal conversion of solar energy. Finally, the drying temperature is established as a function of the maximum limit of temperature the material might support. 
The drying chamber of a drier consists of meshes on which product is spread for drying. Also, the drying chamber (Youcef-Ali et al., 2004) is a wooden cabinet. Hence, the heat loss to the side walls of the drying chamber is considered. As the hot air passes through the mesh, in forced convection driers, turbulence is created. A solar drier without either heat storage or air recycling is considered with a solar collector containing offset plate fins. Experiments are conducted to calculate heat losses (through Nusselt number).

In the above models, the variation of incoming solar radiation is not taken into account. For modeling purpose, a constant artificial flux is adopted to study the drying phenomenon (Hachemi, et al., 1998). A drier with three beds of wool is considered with a solar collector. The drying process in the three zones of the bed is theoretically analyzed. The solar collector is equipped with a flat plate absorber and offset plate fins absorber plate. Under constant incident fluxes, at the same mass flow rate of air, the drying rate and time has been studied to find that offset plate fins collector is better.

The known facts that, the inlet temperature of the air is variable (because of variable incoming solar radiation) and the products shrink as drying process continues are taken into consideration for modeling (Ratti and Mujumdar, 1997). A most common cabinet type drier is considered for the study. A moving co-ordinate is defined to take into account of the shrinkage effects. The experimental data from previous workers is considered for validation of the mathematical model. The carrot cubes are used as product to test the model. It is proposed that the estimation of solar irradiance on the drier is essential to predict the response of the drier (Garg and Kumar, 1998). Considering a semi-cylindrical solar tunnel drier, the irradiance is calculated by taking the geometric quantities, relative motion of sun and optical properties into account.

The change of main variables such as moisture content along the drying tunnel is considered unlike in previous works where uniform distribution is assumed (Condori and Saravia, 2003). This is a study of tunnel green house drier which is continuous type. The conditions for improvement of efficiency are evaluated. A linear relationship between the tunnel output temperature and incident solar radiation is obtained. The drier production is presented by a performance parameter which is defined as the ratio between the energy actually used in the evaporation and the total available energy for the drying process. A non-dimensional variable is also defined, which has all the meteorological information. It is found that, the average moisture content value of the tunnel can be considered to be constant (Murthy, 2009).

The construction and working of solar tunnel drier is explained in detail. Three fans run by a solar module are used to create forced convection. The drying procedure and the instrumentation are also described. The major advantage of solar tunnel drier is that the regulation of the drying temperature is possible. During high insolation periods, more energy is received by the collector, which tends to increase the drying temperature and is compensated by the increase of the air flow rate. The variation of voltage with respect to radiation in a given day and variation of radiation with respect to time of the day are presented. The comparative curves using the tunnel dryer and natural sun drying are presented to show that, the tunnel drying time is less(Murthy, 2009). A substantial increase in the average sugar content is observed. The economics of the drier is worked out to show that, the pay back period is 3 years.

The solar tunnel drier is modified to develop a green house tunnel drier whose working principle and construction is explained in detail. Some additional features of the tunnel drier 
are high lighted such as improvement in the drier efficiency, lowering of the labor cost and ease in installing a conventional heater as an auxiliary heating system for continuous production (Condori et al., 2001). The drier is considered as a solar collector, and its instantaneous efficiency is measured. Products were dried in various configurations, i.e., cut in various ways. The plots of time in a given day vs. moisture content are plotted. The working principle of auxiliary heating system is also presented.

Through out the literature, decrease in drying time has been the main concern. Further, the natural convection type drier is not preferred as low buoyancy forces may cause reverse effect leading to the spoilage of the product. In order to resolve these two issues, an integral type natural convection drier coupled with a biomass stove is developed (Prasad and Vijay, 2005). The constructional details and operation of the drier are presented in detail. Drying time was lowest for solar-biomass method. The uniformity of drying was questionable as there was significant variation in moisture content when samples were tested from trays at top, middle and bottom. Even within a tray, when temperature, relative humidity and velocity of air were measured, variations were observedThe drying efficiency of the drier was evaluated and it is noted that, type of product and its final moisture content level influences the drying efficiency. The final moisture in a product generally requires more energy to extract than the initial moisture and the preparation of the products prior to drying such as slicing, boiling affects the drying efficiency. These factors make it difficult to make comparisons with the drying efficiencies of other solar driers reported in the literature.

\section{Conclusions}

This chapter is focused on the available solar dryer's systems and new technologies. The dependence of the drying on the characteristics of product remains still as a problem, for comparison of drying efficiencies of various driers. Author presented a comprehensive review of the various designs, details of construction and operational principles of the wide variety of practically realized designs of solar-energy drying systems. Two broad groups of solar-energy dryers can be identified, viz., passive or natural-circulation solar-energy dryers and active or forced-convection solar-energy dryers (often called hybrid solar dryers). Three sub-groups of these, which differ mainly on their structural arrangement, can also be identified, viz integral or direct mode solar dryers, distributed or indirect-modes. This classification illustrates clearly how these solar dryer designs can be grouped systematically according to either their operating temperature ranges, heating sources and heating modes, operational modes or structural modes. Though properly designed forced-convection (active) solar dryers are agreed generally to be more effective and more controllable than the natural-circulation (passive) types. This chapter also presents some easy-to-fabricate and easy-to-operate dryers that can be suitably employed at small-scale factories. Such low-cost drying technologies can be readily introduced in rural areas to reduce spoilage, improve product quality and overall processing hygiene.

\section{References}

Bal, L. M., Satya, S., Naik, S.N., Solar dryer with thermal energy storage systems for drying agricultural food products: A review. Renewable and Sustinable Energy Reviews, Vol.14(8), pp. 2298-2314. 
Bena, B., Fuller, R.J., 2002. Natural convection solar dryer with biomass back-up heater. Solar Energy, Vol.72, pp. 75-83.

Condori, M., Echazu, R., Saravia, L., 2001. Solar drying of sweet pepper and garlic using the tunnel greenhouse drier. Renewable Energy, Vol.22, pp. 447-460.

Condori, M., Saravia, L., 2003. Analytical model for the performance of the tunnel-type greenhouse drier. Renewable Energy, Vol.28, pp. 467-485.

Ekechukwu, O.V., Norton, B., 1999. Review of solar-energy drying systems II: an overview of solar drying technology. Energy Conversion \& Management, Vol.40(6), pp. 615-655.

Garg, H.P., Kumar, R., 1998. Studies on semi-cylindrical solar tunnel dryers: estimation of solar irradiance. Renewable Energy, Vol.13, pp. 393-400.

Goyal, R.K., Tiwari, G.N., 1999. Performance of a reverse flat plate absorber cabinet dryer: a new concept. Energy Conversion \& Management, Vol.40(4), pp. 385-392.

Hachemi, A., Abed, B., Asnoun, A., 1998. Theoretical and experimental study of solar dryer. Renewable Energy, Vol.13, pp. 439-451.

Hallak, H., Hilal, J., Hilal, F., Rahhal, R., 1996. The staircase solar dryer: design and characteristics. Renewable Energy, Vol.7, pp. 177-183.

Janjai, S., Tung, P., 2005. Performance of a solar dryer using hot air from roof-integrated solar collectors for drying herbs and spices. Renewable Energy, Vol.30, pp. 20852095.

Koyuncu, T., 2006. Performance of various design of solar air heaters for drying applications. Renewable Energy, Vol.31, pp. 1073-1088.

Koyuncu, T., 2006. An investigation on the performance improvement of green house type agricultural dryers. Renewable Energy, Vol.31, pp. 1055-1071.

McDoom, I.A., Ramsaroop, R., Saunders, R., Tang Kai, A., 1999. Optimization of solar drying. Renewable Energy, Vol.16, pp. 749-752.

Mumba, J., 1995. Development of a photovoltaic powered forced circulation grain dryer for use in the tropics. Renewable Energy, Vol. 6(7), pp.855-862.

Murthy, R. 2009. A review of new technologies, models and experimental investigations of solar driers. Renewable and Sustinable Energy Revıews, Vol.13, pp. 835-844.

Othman, M.Y.H, Sopian, K., Yatim, B., Daud, W.RW., 2006. Development of advanced solar assisted drying systems. Renewable Energy, Vol.31, pp. 703-709.

Prasad, J., Vijay, V.K., 2005. Experimental studies on drying of Zingiber officinale, Curcuma longa and Tinospora cordifolia in solar-biomass hybrid drier. Renewable Energy, Vol.30, pp. 2097-2109.

Ratti, C., Mujumdar, A.S., 1997. Solar drying of foods: modeling and numerical simulation. Solar Energy, Vol.60, pp. 151-157.

Sarsilmaz, C., Yildiz, C., Pehlivan, D., 2000. Drying of apricots in a rotary column cylindrical dryer (RCCD) supported with solar energy. Renewable Energy, Vol.21, pp. 117-127.

Singh, S., Singh, P.P., Dhaliwal, S.S,. 2004. Multi-shelf portable solar dryer. Renewable Energy, Vol.29, pp. 753-765.

Shanmugam, V., Natarajan, E., 2006. Experimental investigation of forced convection and desiccant integrated solar dryer. Renewable Energy, Vol.31, pp. 1239-1251.

Sharma, A., Chen, C. R., Vu Lan, N., 2009. Solar- energy drying systems:A review. Renewable and Sustinable Energy Reviews, Vol.13, pp. 1185-1210. 
Sodha, M.S., Dang, A., Bansal, P.K., Sharma, S.B., 1985. An analytical and experimental study of open sun drying and a cabinet type drier. Energy Conversion $\mathcal{E}$ Management,, Vol.25(3), pp. 263-271.

Thoruwa, T.F.N., Johnstone, M.C., Grant, A.D., Smith, J.E., 2000. Novel, low cost CaCl2 based desiccants for solar crop drying applications. Renewable Energy, Vol.19, pp. 513-520.

Xie, W.T., Dai Y.J., Wang, R.Z., Sumathy, K., 2011. Concentrated solar energy applications using Fresnel lenses: A review Renewable \& Sustannable Energy Reviews, Vol. 15(6), pp. $2588-2606$.

Torres-Reyes, E., Gonzalez, N.J.J., Ibarra-Salazar, B.A., 2002. Thermodynamic method for designing dryers operated by flat plate solar collectors. Renewable Energy, Vol.26. pp. 649-660.

Youcef-Ali, S., Desmons, J.Y., 2004. Daguenet M. The turbulence effect of the airflow on the calorific losses in foodstuff dryers. Renewable Energy, Vol.29, pp.661-674. 


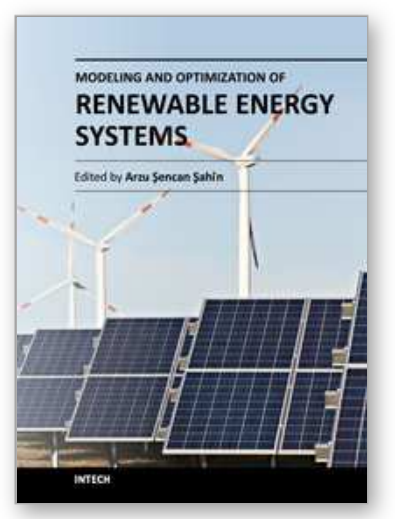

\author{
Modeling and Optimization of Renewable Energy Systems \\ Edited by Dr. Arzu Şencan
}

ISBN 978-953-51-0600-5

Hard cover, 298 pages

Publisher InTech

Published online 11, May, 2012

Published in print edition May, 2012

This book includes solar energy, wind energy, hybrid systems, biofuels, energy management and efficiency, optimization of renewable energy systems and much more. Subsequently, the book presents the physical and technical principles of promising ways of utilizing renewable energies. The authors provide the important data and parameter sets for the major possibilities of renewable energies utilization which allow an economic and environmental assessment. Such an assessment enables us to judge the chances and limits of the multiple options utilizing renewable energy sources. It will provide useful insights in the modeling and optimization of different renewable systems. The primary target audience for the book includes students, researchers, and people working on renewable energy systems.

\title{
How to reference
}

In order to correctly reference this scholarly work, feel free to copy and paste the following:

Feyza Akarslan (2012). Solar-Energy Drying Systems, Modeling and Optimization of Renewable Energy Systems, Dr. Arzu Şencan (Ed.), ISBN: 978-953-51-0600-5, InTech, Available from:

http://www.intechopen.com/books/modeling-and-optimization-of-renewable-energy-systems/solar-energydrying-systems-and-applications

\section{INTECH}

open science | open minds

\author{
InTech Europe \\ University Campus STeP Ri \\ Slavka Krautzeka 83/A \\ 51000 Rijeka, Croatia \\ Phone: +385 (51) 770447 \\ Fax: +385 (51) 686166 \\ www.intechopen.com
}

\author{
InTech China \\ Unit 405, Office Block, Hotel Equatorial Shanghai \\ No.65, Yan An Road (West), Shanghai, 200040, China \\ 中国上海市延安西路65号上海国际贵都大饭店办公楼 405 单元 \\ Phone: +86-21-62489820 \\ Fax: +86-21-62489821
}


(C) 2012 The Author(s). Licensee IntechOpen. This is an open access article distributed under the terms of the Creative Commons Attribution 3.0 License, which permits unrestricted use, distribution, and reproduction in any medium, provided the original work is properly cited. 